\title{
An Effector, BxSapB1, Induces Cell Death and Contributes to Virulence in the Pine Wood Nematode Bursaphelenchus xylophilus
}

\author{
Long-Jiao Hu, ${ }^{1,2}$ Xiao-Qin Wu, ${ }^{1,2,+}$ Hai-Yang Li, ${ }^{3}$ Qun Zhao, ${ }^{1,2}$ Yuan-Chao Wang, ${ }^{3}$ and Jian-Ren Ye ${ }^{1,2}$ \\ ${ }^{1}$ Co-Innovation Center for Sustainable Forestry in Southern China, College of Forestry, Nanjing Forestry University, Nanjing, \\ 210037, China; ${ }^{2}$ Jiangsu Key Laboratory for Prevention and Management of Invasive Species, Nanjing Forestry University; and \\ ${ }^{3}$ Department of Plant Pathology, Nanjing Agricultural University, Nanjing 210095, China
}

Accepted 20 October 2018.

\begin{abstract}
The pine wood nematode (PWN) Bursaphelenchus xylophilus has caused serious damage to pine forests in China. Effectors secreted by phytonematodes play a role in host infection. We identified and characterized an effector, BxSapB1, based on the B. xylophilus transcriptome at the early stages of infection and the transient expression of proteins in Nicotiana benthamiana. BxSapB1 triggered cell death in $N$. benthamiana when secreted into the apoplast, and this effect was independent of $N$. benthamiana brassinosteroid-insensitive 1-associated kinase 1 (NbBAK1) and suppressor of BIR1-1 (NbSOBIR1). The signal peptide of $B x S a p B 1$ was proven to be functional in yeast using the yeast signal sequence trap system and $B x$ SapB 1 was strongly expressed in the subventral gland cells of $B$. xylophilus, as revealed by in-situ hybridization. In addition, based on local BLAST analysis, the BxSapB1 showed $100 \%$ identity to BUX. s00139.62, which was identified from the $B$. xylophilus secretome during Pinus thunbergii infection. BxSapB1 was upregulated in a highly virulent strain and downregulated in a weakly virulent strain of PWN at the early stages of infection. RNA interference assays showed that silencing $B x S a p B 1$ resulted in decreased expression of pathogenesis-related genes (PtPR-1b, PtPR-3, and PtPR-5) as well as delayed onset of symptoms in $P$. thunbergii infected by $B$. xylophilus. The combined data suggest that BxSapB1 can trigger cell death in $N$. benthamiana and that it contributes to the virulence in $B$. xylophilus during parasitic interaction.
\end{abstract}

Keywords: Bursaphelenchus xylophilus, cell death, effector, RNA interference, transcriptome sequencing, virulence

Pine wilt disease (PWD) is one of the most serious coniferous forest diseases worldwide and has resulted in massive economic losses in Asian and European countries, especially China and Japan (Hunt 2009; Jones et al. 2013; Vicente et al. 2011).

${ }^{\dagger}$ Corresponding author: X.-Q. Wu: E-mail: xqwu@njfu.edu.cn

Funding: This work was supported by the National Key Research and Development Program of China (2018YFD0600203), Jiangsu Provincial Agricultural Science and Technology Innovation Fund (CX [16] 1005), and the Priority Academic Program Development of Jiangsu Higher Education Institutions (PAPD).

*The $\boldsymbol{e}$-Xtra logo stands for "electronic extra" and indicates that five supplementary figures and six supplementary tables are published online.

(c) 2019 The American Phytopathological Society
PWD is caused by one of the most notorious migratory plantparasitic nematodes, the pine wood nematode (PWN) Bursaphelenchus xylophilus. The feeding strategy of B. xylophilus includes phytophagous and mycophagous stages, which distinguishes it from other plant-parasitic nematodes and enables it to reproduce and survive in its host. At the phytophagous stage, the nematode migrates to the xylem resin and ray canals and feeds on parenchyma cells, leading to cell death (Mamiya 2012). As part of a strong defense response during the early stages of infection, the tree releases polyphenolic compounds (causing yellowing and browning of the tree needles during infection), terpenoids, reactive oxygen species, and lipid peroxides (Fukuda, 1997). As the number of nematodes increases, water transport through the infected tree is compromised, leading to wilt and, ultimately, death of the tree. As the tree dies, the nematode changes to the mycophagous stage and feeds on the fungi that colonize the tree (Jones et al. 2008).

A great deal of research on this disease has been conducted to date on topics such as host resistance, the B. xylophilus life cycle, insect vectors (Monochamus beetles), and disease epidemiology. Although some parasitism genes and plant cell wall-degrading enzymes of B. xylophilus have been suggested to play a role in the interactions between pines and nematodes, the mechanisms of pathogenesis remain unclear (Haegeman et al. 2012; Oh et al. 2009; Smant et al. 1998; Xiong et al. 2009; $\mathrm{Xu}$ et al. 2015). Many studies suggest that effectors secreted by pathogens play a key role in the infection process ( $\mathrm{Li}$ et al. 2015b; Ma et al. 2015; Zhang et al. 2017).

Various pathogens and parasites, including oomycetes, bacteria, and plant-parasitic nematodes, can secrete a series of effectors to promote infection. Despite numerous biological differences among these pathogens, the molecular interactions among them and their hosts, are governed by certain shared principles (Ali et al. 2015a). Pattern recognition receptors (PRRs), including leucine-rich repeat (LRR) receptor-like proteins and LRR receptor-like kinase (LRR-RLK), can recognize conserved pathogen-associated molecular patterns (PAMPs) and microbe-associated molecular patterns to trigger immunity (Jones and Dangl 2006). LRR-RLK brassinosteroidinsensitive 1-associated kinase 1 (BAK1) and suppressor of BIR1-1 (SOBIR1) are coreceptors of multiple PRRs and participate in several types of PAMP-triggered immune signaling pathways (Heese et al. 2007; Liebrand et al. 2014). Hostadapted pathogens secrete effector proteins to suppress PAMPtriggered immunity to successfully infect hosts. Recognition of the effectors by disease-resistance genes triggers the second overlapping mode of innate immunity (effector-triggered 
immunity) in plants (Chisholm et al. 2006; Jones and Dangl 2006). In general, the effectors can be secreted to the host cytoplasm and apoplast (Ali and Bakkeren 2011; Ali et al. 2015a; Zhang and $\mathrm{Xu}$ 2014). Fewer studies have been conducted on apoplastic effectors as compared with cytoplasmic effectors, even though the former have proven to be very important in pathogen-host interactions (Eves-van den Akker et al. 2014; Jaubert et al. 2005; Lozano-Torres et al. 2014; Ma et al. 2015; Vieira et al. 2011).

The phytonematodes include sedentary and migratory endoparasitic phytonematodes. The effectors from the former have been studied in depth for more than two decades (Bauters et al. 2014; Chen et al. 2015; Chronis et al. 2013; Haegeman et al. 2013; Hussey 1989; Hussey and Mims 1990; Patel et al. 2010). Some of these known effectors can modify host cells and facilitate the ingestion of nutrients to sustain growth and development (Bauters et al. 2014; Chen et al. 2015; Chronis et al. 2013; Haegeman et al. 2013; Mitchum et al. 2013; Patel et al. 2010) and some of them can change the host-plant signaling pathway to suppress plant defense responses (Ali et al. 2015a; Chen et al. 2015, 2017). Preliminary studies have been conducted on effectors from several migratory endoparasitic nematodes. For instance, two Ditylenchus destructor effectors have been characterized, and it has been shown that Rs-CRT (Radopholus similis calreticulin) is a key effector for reproduction and pathogenicity in Radopholus similis (Li et al. 2015a; Peng et al. 2013). Some parasitism genes and plant cell wall-degrading enzymes normally regarded as 'effectors' have been characterized from $B$. xylophilus, such as glycoside hydrolase family 45 cellulases, pectate lyases, expansins, and $\beta$-1,3-endoglucanases (Kikuchi et al. 2004, 2005, 2006; Li et al. 2009). However, studies on B. xylophilus effectors and their role in woody pine infection are scarce. There is an urgent need to investigate issues such as whether $B$. xylophilus secretes effectors like those of other phytonematodes, how to accurately and rapidly identify such effectors, and how hosts respond to them.

Although candidate $B$. xylophilus effectors have been predicted by comparing transcriptomes between the mycetophagous and phytophagous parasitic stages ( 6 and 15 days after inoculation, respectively), their functions have not been further studied (Espada et al. 2016). Moreover, previous studies showed that reactive oxygen species could trigger the hypersensitive response and cell death (Ali et al. 2015b; Hancock et al. 2002; Lebeda et al. 2008). In Pinus thunbergii, $\mathrm{H}_{2} \mathrm{O}_{2}$ and NO increased rapidly at 8 and $12 \mathrm{~h}$, respectively, after B. xylophilus infection (Yu et al. 2012a). Programmed cell death was also observed at $12 \mathrm{~h}$ postinfection in parenchymatous cells of the $P$. thunbergii cortex (Li and Ye 2008). This suggested that some effectors might have been secreted into host cells at an earlier stage.

The main sphingolipid activator proteins (SAPs) are saposins A, B, C, and D, which are derived from a common precursor, prosaposin. They are small, heat-stable lysosomal glycoproteins necessary for the lysosomal degradation of specific sphingolipids (Yuan et al. 2007). Previous studies demonstrated that sphingolipids played key roles in signal transduction and the response to biotic or abiotic stresses in plants (Bi et al. 2014; Li et al. 2016; Zhang et al. 2013) and SAPs participated in the lysis of host cells for nutrition uptake in the trematodes Fasciola hepatica and Clonorchis sinensis (Espino and Hillyer 2003; Lee et al. 2002). Saposin $\mathrm{B}$ facilitates the degradation of a variety of lipids, including sulfatide by arylsulfatase A and globotriaosylceramide and digalactosylceramide by galactosidase A (Li et al. 1985). At present, the functions of SAPs in B. xylophilus have not yet been studied.
In the present study, we conducted an analysis of the B. xylophilus transcriptome during early infection to identify candidate effectors. Subsequently, we characterized the transient expression of candidate effectors via a potato virus $\mathrm{X}$ (PVX) expression vector in Nicotiana benthamiana. In addition, whether the effector-induced cell death depends on common coreceptors NbBAK1 or NbSOBIR1 was studied, to investigate the signaling pathways of cell death in $N$. benthamiana. The spatial location of the effector was confirmed by in-situ hybridization, and expression patterns were measured in strains of different virulence. RNA interference (RNAi) assays revealed the function and influence of the effector on host defense responses. Finally, we characterized an effector of B. xylophilus, BxSapB1, which could trigger cell death in $N$. benthamiana and contributed strongly to virulence in $B$. xylophilus. The present study sheds new light on the complex interactions between pine and B. xylophilus.

\section{RESULTS}

Identification of candidate $B$. xylophilus effectors during early infection using RNA-sequencing (RNA-Seq).

A suspension of approximately 10,000 mixed-life-stage nematodes were collected from the potato dextrose agar (PDA) as mycophagous control (bx-0 h). In addition, the same numbers of nematodes were inoculated into a small wound in each of the pine stems for $6 \mathrm{~h}(\mathrm{bx}-6 \mathrm{~h}), 12 \mathrm{~h}(\mathrm{bx}-12 \mathrm{~h})$, and $24 \mathrm{~h}$ (bx-24 h). Nematode RNA was extracted from these samples to construct RNA-Seq libraries. In total, we generated $592,991,982$ raw reads from 12 samples, by Illumina sequencing; 570,138,674 clean reads were retained after removing low-quality sequences (Supplementary Table S1). Differentially expressed genes (DEGs) were identified between the early stages of infection $(6,12$, and $24 \mathrm{~h}$ postinfection) and the mycetophagous stage $(0 \mathrm{~h})$. A total of 867 DEGs were obtained, of which 247 were upregulated at least at one of the plant-parasitic timepoints compared with the mycophagous stage (Fig. 1). RNA-Seq data were further verified by quantitative real-time polymerase chain reaction (qRT-PCR) (Supplementary Fig. S1). It was predicted that 69 of the 247 genes contained signal peptides but no transmembrane domains. Forty-nine potentially secreted proteins were matched against the SWISS-PROT database by BLAST search, and some were found to be proteases (Supplementary Table S2). Moreover, the 69 candidate effectors obtained from this study were compared with the PWN candidate effectors dataset obtained in a previous study (Espada et al. 2016); four of the effectors predicted here were also regarded as candidate effectors in the previous study (Supplementary Table S3).

\section{BxSapB1 triggers cell death in $N$. benthamiana when secreted into the apoplast.}

To identify candidate effectors, 25 randomly selected, highly expressed candidate effectors with signal peptides were ligated into the PVX vector. Then, these constructs were inserted into Agrobacterium tumefaciens GV3101 by electroporation. The $A$. tumefaciens cultures (optical density at $600 \mathrm{~nm}\left[\mathrm{OD}_{600}\right]=0.4$ ) were infiltrated into $N$. benthamiana with a needleless syringe to overexpress the 25 candidate effectors (Supplementary Table S4). Among them, only one (BXY_0583800) significantly triggered cell death, which was determined to contain a SapB domain using the Simple Modular Architecture Research Tool (SMART). Its open reading frame contains 435 base pairs (bp) and encodes a 145-amino acid polypeptide, which was chosen for further study and denoted as BxSapB1.

As the RXLR effector of Phytophthora sojae, Avh238 86497 triggers cell death in $N$. benthamiana (Yang et al. 2017), it and 
green fluorescent protein (GFP) were used as the positive and negative controls, respectively, in the transient assay. The result 7 days after infiltration indicated that BxSapB1 and Avh238 ${ }^{\mathrm{P} 6497}$ induced cell death in $N$. benthamiana (Fig. 2A).

A yeast signal trap system based on the requirement of yeast cells for invertase secretion to grow on sucrose or raffinose media was used to validate the functions of the signal peptide of BxSapBl (Jacobs et al. 1997). The predicted signal peptide sequence of $B x S a p B l$ was fused in frame to the mature sequence of yeast invertase in the vector pSUC2T7M13ORI (pSUC2), with a truncated invertase gene, $S U C 2$, without the initiation Met and signal peptide (Jacobs et al. 1997). The signal peptide of Phytophthora infestans RXLR effector Avrblb2 was proven to be functional in yeast, which was used as the positive control (Oh et al. 2009). The untransformed YTK12 strain and YTK12 with pSUC2 vector were used as negative controls. pSUC2-Avrblb2sp and pSUC2-BxSapB1sp facilitated the growth of the invertase mutant yeast strain YTK12 on CMD-W (0.67\% yeast $\mathrm{N}$ base without amino acids, $0.075 \% \mathrm{~W}$ dropout supplement, $2 \%$ sucrose, $0.1 \%$ glucose, and $2 \%$ agar) and YPRAA (1\% yeast extract, $2 \%$ peptone, $2 \%$ raffinose, and $2 \mu \mathrm{g} / \mathrm{ml}$ antimicyn $\mathrm{A}$ ) media, and insoluble redcolored triphenylformazan was generated after treatment with 2,3,5-triphenyltetrazolium chloride (TTC). In contrast, the strain with empty vector pSUC2 could grow on CMD-W medium but not the wild strain YTK12. Moreover, both strains grew to a limited extent on YPRAA, and their TTC-treated culture filtrate remained colorless (Fig. 2B). These results indicated that the signal peptide of $\mathrm{BxSapB} 1$ was functional in yeast.

Pathogenesis-related (PR) proteins are expressed in many plants reacting hypersensitively toward various pathogens and, in tobacco, these PRs were proven to be localized predominantly in the apoplast (van Loon 1985). To determine

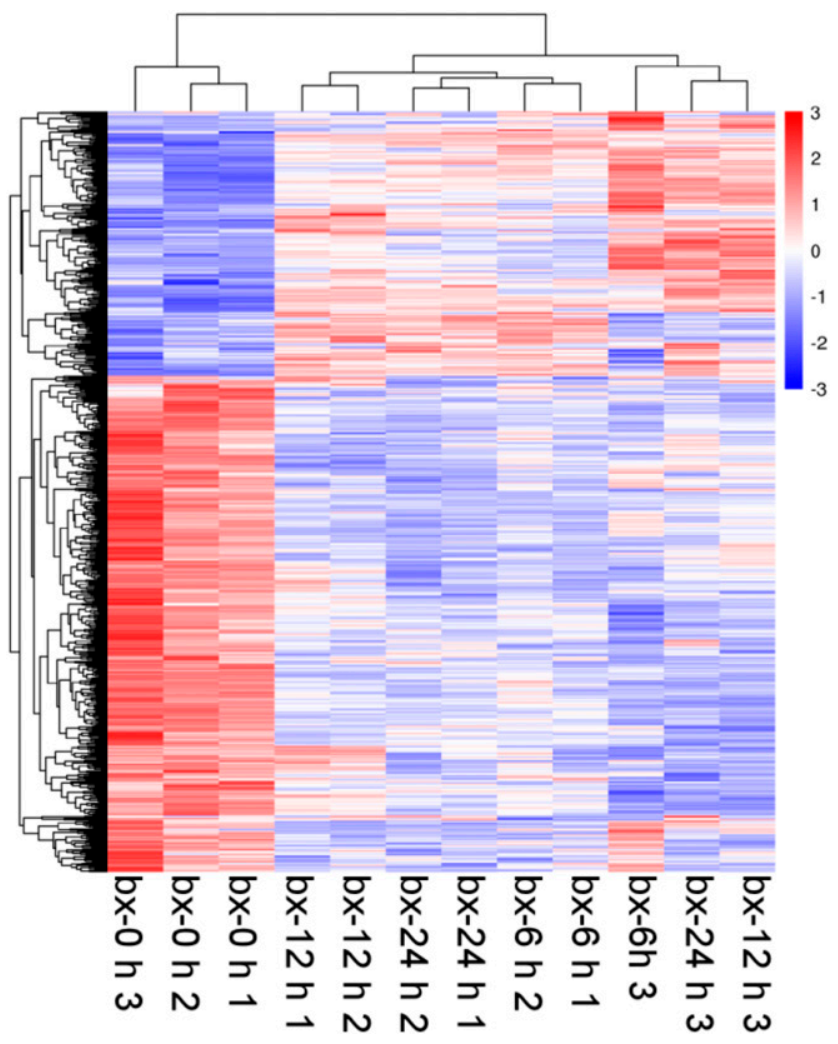

Fig. 1. Heatmap of the differentially expressed genes at the mycetophagous stage and three early phytophagous parasitic stages. whether BxSapB1 was secreted to the apoplast to trigger cell death, the N-terminal signal peptide was deleted to produce BxSapB1nsp and, then, the signal peptide from PR protein 1 (PR1) of N. tabacum (Supplementary Table S5) was added to produce PR1 SP-BxSapB1nsp (Fig. 2C). In the transient assays, the results showed that BxSapB1 and PR1 SP-BxSapB1nsp but not BxSapB1nsp triggered cell death in N. benthamiana (Fig. 2D). Expression of these proteins was validated by Western blot analysis (Fig. 2E). Ion leakage measurements were used to quantify the degree of cell death triggered by the four tested proteins. Electrolyte leakage induced by BxSapB1 and PR1 SP-BxSapB1nsp were significantly higher than that induced by BxSapB1nsp or GFP (Fig. 2F). The data indicated that BxSapB1 triggered cell death in $N$. benthamiana when secreted to the apoplast.

\section{BxSapB1-triggered cell death does not depend on NbBAK1 or NbSOBIR1.}

BAK1 and SOBIR1 are coreceptors of different PRRs, which can recognize PAMPs. A previous study showed that both the PAMP INF1, secreted by Phytophthora infestans, and the PAMP RcCDI1, from Rhynchosporium commune, induced cell death in the apoplast of $N$. benthamiana, and this response required the PRRs NbBAK1 and NbSOBIR1 (Franco-Orozco et al. 2017; Heese et al. 2007). Our study suggests that BxSapB1 induces cell death when secreted into the apoplast in $N$. benthamiana. However, it is still unclear whether BxSapB1 is a PAMP and whether NbBAK1 and NbSOBIR1 both participate in BxSapB1-triggered cell death. Thus, $N b B A K 1$ and NbSOBIRl were silenced in $N$. benthamiana, using virusinduced gene silencing (VIGS).

In the VIGS assays, pTRV1, pTRV2:BAK1, pTRV2:SOBIR1, pTRV2:GFP, and pTRV2:PDS plasmid constructs were transformed into A. tumefaciens GV3101, and then, Agrobacterium strains harboring the vectors above were first mixed with the strain harboring pTRV1 vector with a 1:1 ratio. The cocultures were then infiltrated into all leaves of a plant at the four-leaf stage. Three to four weeks after infiltration with the VIGS constructs, the silencing efficiency of $N b B A K 1$ and $N b S O B I R 1$ were validated by qRT-PCR analysis of cDNA from the leaves of three plants that were silenced and control $N$. benthamiana (Fig. 3A). The BAK1 and SOBIR1 were not required for necrosis-inducing Phytophthora protein 1 (NPP1)-triggered cell death in N. benthamiana (Wang et al. 2018). Thus, INF1 and NPP1 were used as negative and positive control, respectively. As expected, INF1 induced cell death in $G F P$-silenced plants but not in NbBAK1 and NbSOBIR1-silenced plants. However, NPP1 and $\mathrm{BxSapB} 1$ could trigger cell death in all the silenced plants by the three VIGS constructs (Fig. 3B). Moreover, Western blot analysis verified that all assayed proteins were expressed in all the silenced $N$. benthamiana (Fig. 3C). These results indicated that NbBAK1 and NbSOBIR1 did not participate in BxSapB1triggered cell death.

\section{BxSapB1 is expressed}

in the subventral gland cells of $B$. xylophilus.

Increasing evidences indicated that the pharyngeal gland cells were the source of the majority of nematode effectors (Haegeman et al. 2012). To explore the spatial expression patterns of $B x S a p B 1$, in-situ hybridization with a digoxigenin (DIG)-labeled antisense probe was used. The results revealed a clear color signal in the subventral gland cells of B. xylophilus, but no signal was observed in the negative control (Fig. 4; Supplementary Fig. S2). This suggests that BxSapB1 is delivered as a secreted protein into host cells at the infection stage. 


\section{Diverse expression patterns of $\mathrm{BxSapB1}$} at the early stages of infection by $B$. xylophilus strains with different levels of virulence.

The previous findings suggested that there are highly and weakly virulent PWN strains (Akiba et al. 2012). To determine whether BxSapB1 differs in PWN strains of differing virulence, we isolated its cDNA from strains AMA3 (highly virulent strain) and YW4 (weakly virulent strain) (Ding et al. 2016) and determined its relative expression levels in both strains. The sequencing result revealed that BxSapB1 sequences from AMA3 and YW4 were identical. However, the qRT-PCR results showed that $B x S a p B 1$ expression increased significantly in the highly virulent strain AMA3 at $12 \mathrm{~h}$ after inoculation. In contrast, it was expressed at low levels in the weakly virulent strain YW4 throughout the entirety of early infection (Fig. 5). This suggested that $B x S a p B 1$ might influence the virulence of B. xylophilus.

\section{$B x$ SapB1 contributes to virulence during infection.}

BxSapB1 RNAi nematodes were used in infection assays to explore the contribution of BxSapB1 to the virulence of B. xylophilus. The double-stranded RNA (dsRNA) soaking method was performed to silence BxSapB1 and GFP. The nematodes were soaked in 800-ng/ $\mu \mathrm{l} B x S a p B 1$ dsRNA, GFP

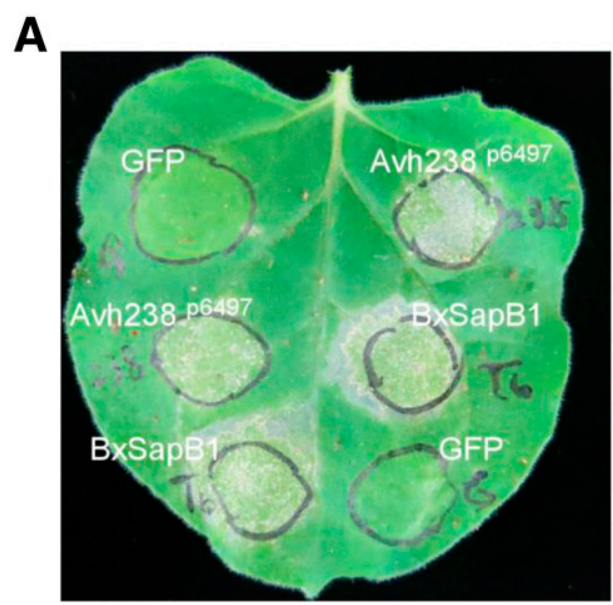

B

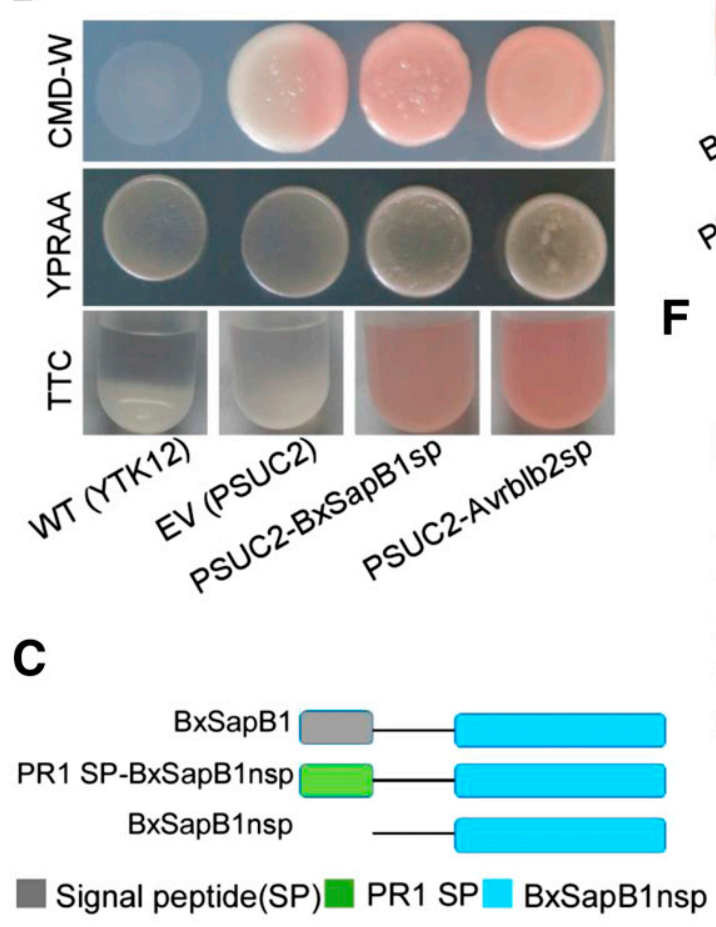

D

$\mathbf{F}$
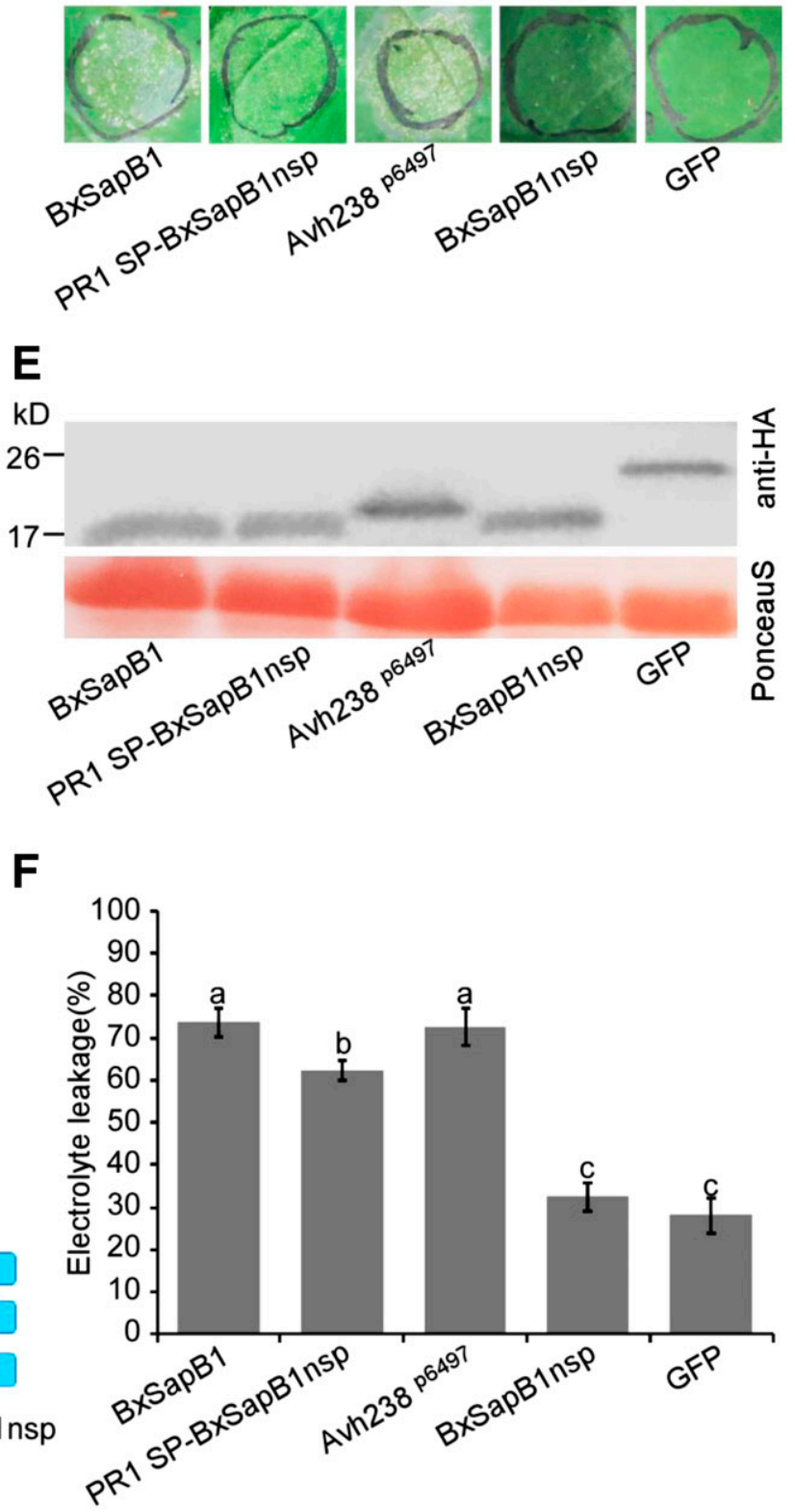

Fig. 2. Candidate effector BxSapB1 causes cell death when secreted to the apoplast in Nicotiana benthamiana. A, Representative $N$. benthamiana leaves at 7 days after inoculation with Agrobacterium sp. strain GV3101 carrying BxSapB1 in vector pGR107. The infiltration assay was performed three times and, in each assay, three different plants with three inoculated leaves were used. B, Functional validation of the signal peptides of BxSapB1. C, Regions of BxSapB1 examined for cell-death activity. D, Representative $N$. benthamiana leaves at 7 days after agroinfiltration carrying BxSapB1nsp and pathogenesis-related protein 1 (PR1) SP-BxSapB1nsp. The infiltration assay was performed three times and, in each assay, three different plants with three inoculated leaves were used. E, Immunoblot analysis of proteins from $N$. benthamiana leaves transiently expressing target proteins fused with anti-hemagglutinin (anti-HA) tags. F, Quantification of cell death by measuring electrolyte leakage. Data are the means and the error bars represent \pm standard deviation from three independent experiments. Different letters on top of the bars indicate statistically significant differences $(P<0.01, t$ test $)$ as measured by Duncan's multiple range test. 
dsRNA, and non-dsRNA solutions at $20^{\circ} \mathrm{C}$ for $48 \mathrm{~h}$. For the infection assay, each 3 -year-old $P$. thunbergii seedling was inoculated with approximately 2,000 (a mixture of juveniles and adults) $B x S a p B 1$ dsRNA-treated nematodes, GFP dsRNAtreated nematodes, or non-dsRNA solution-treated (wild-type [WT]) nematodes; the seedlings inoculated with GFP dsRNAtreated nematodes and WT nematodes were used as negative controls and only the seedling inoculated with non-dsRNA solution was used as a blank control. Nematode infection symptoms are manifested as early yellowing of needles. The result showed that this early symptom occurred later in seedlings inoculated with BxSapB1 dsRNA-treated nematodes (Fig. 6A; Supplementary Figs. S4 and S5). Moreover, at 13 days postinoculation, the morbidity and degree of morbidity of $P$. thunbergii seedlings inoculated with BxSapB1 dsRNA-treated nematodes were significantly lower than those of seedlings inoculated with GFP dsRNA-treated nematodes or WT nematodes (Fig. 6B and C). The qRT-PCR analysis verified that $B x S a p B 1$ was silenced successfully; its expression was lower with the BxSapBl dsRNA treatment than with the GFP dsRNA and non-dsRNA solutions (Fig. 6D). These results suggested that $B$. xylophilus pathogenicity was significantly reduced when $B x S a p B 1$ was silenced, indicating that $B x S a p B 1$ contributes to virulence of $B$. xylophilus at the early stages of infection.

To investigate the influence of $B x S a p B 1$ on the reproduction and feeding rate of $B$. xylophilus, ten pairs of virgin female and male B. xylophilus were picked out from BxSapB1 dsRNA solution, GFP dsRNA solution, and non-dsRNA solution to each PDA plate with Botrytis cinerea and were cultured at $25^{\circ} \mathrm{C}$ for 9 days. After extraction from PDA plates using the Baermann funnel method, the numbers of B. xylophilus were counted to calculate their reproduction. The amount of Botrytis cinerea mycelia remaining on the PDA plates was measured and used to determine the feeding rate of $B$. xylophilus (the speed of B. xylophilus feeding on Botrytis cinerea). The similar results obtained from the three treatments indicated that BxSapB1 had little influence on the reproduction and feeding rates of B. xylophilus (Supplementary Fig. S3).
A

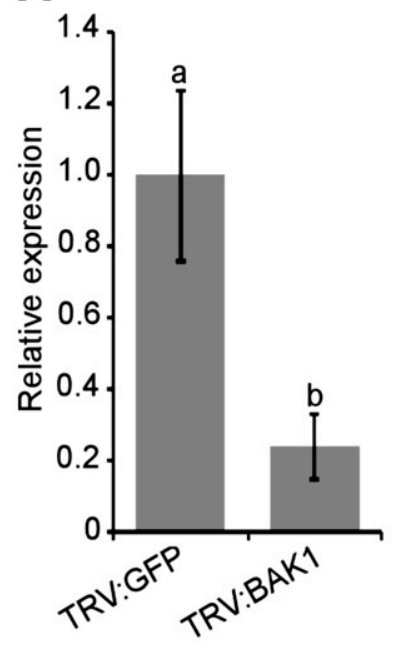

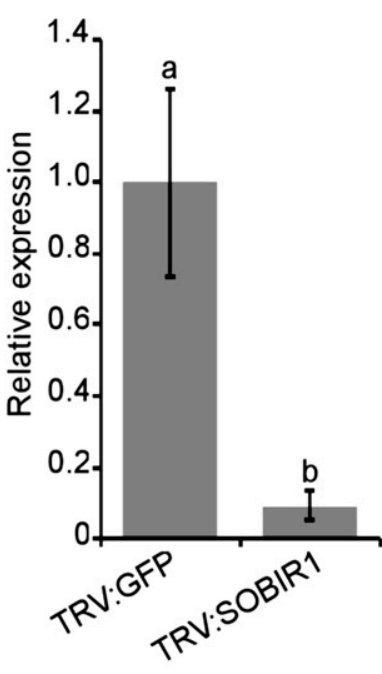

B

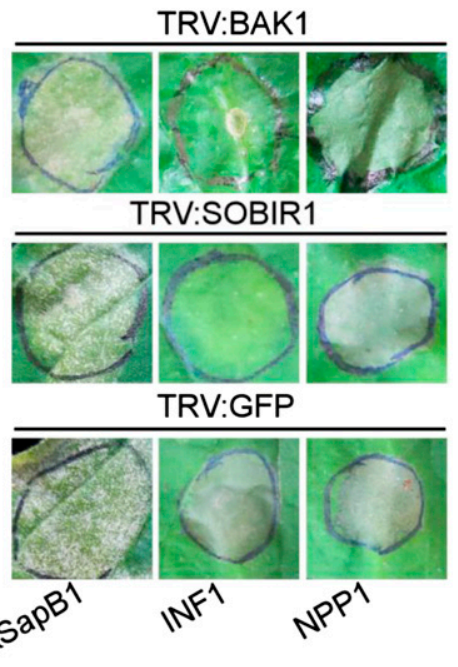

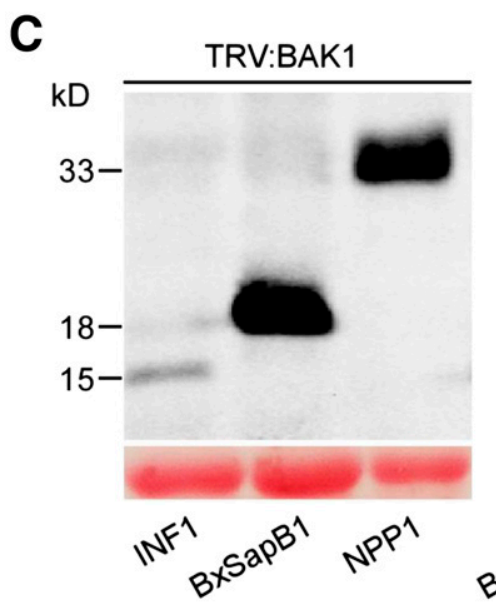
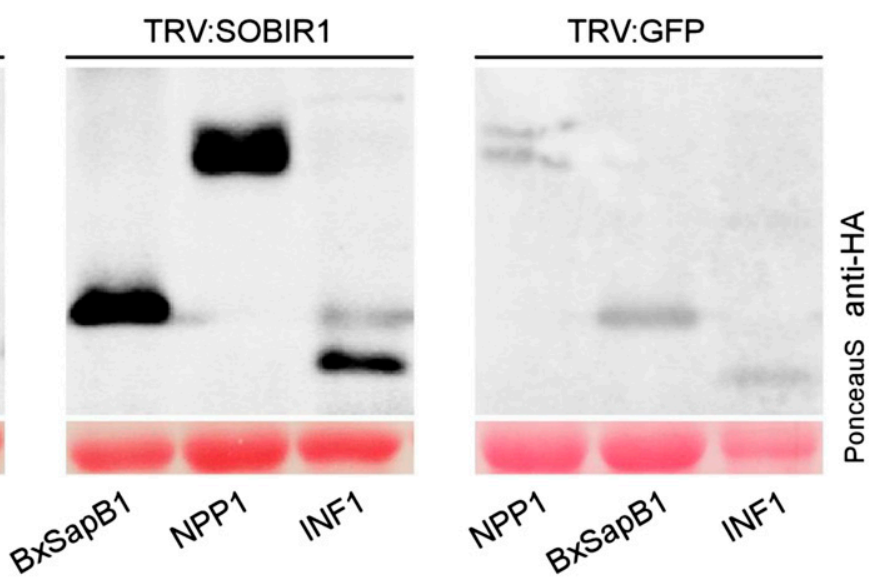

Fig. 3. BxSapB1-triggered cell death independent of Nicotiana benthamiana brassinosteroid-insensitive 1-associated kinase 1 (NbBAK1) or suppressor of BIR1-1 (NbSOBIR1). A, Expression levels of NbBAK1 and NbSOBIR1 after virus-induced gene silencing treatment determined by quantitative real-time polymerase chain reaction analysis. Data are the means and the error bars represent \pm standard deviation from three biological replicates. B, NbBAK1 and NbSOBIR1 are not required for BxSapB1-triggered cell death in $N$. benthamiana. The infiltration assay was repeated three times and, in each assay, three different plants with three inoculated leaves were used. C, Immunoblot analysis of proteins from $N$. benthamiana leaves transiently expressing INF1, NPP1, or BxSapB1 fused with anti-hemagglutinin (anti-HA) tags. Different letters on top of the bars indicate statistically significant differences $(P<0.01, t$ test $)$ as measured by Duncan's multiple range test. 
The relative expression levels of defense-related genes are significantly reduced in $P$. thunbergii infected with $B x S a p B 1$ silenced nematodes.

We tested whether BxSapB1 silencing in B. xylophilus affects expression of PR genes in P. thunbergii (van Loon et al. 2006). Three-year-old $P$. thunbergii seedlings were inoculated with 1,000 BxSapB1 dsRNA-treated or GFP dsRNA-treated nematodes. At $12 \mathrm{~h}$ postinoculation, stems of seedlings approximately $2 \mathrm{~cm}$ in length were collected from $1 \mathrm{~cm}$ below the inoculation spots and were used for RNA extraction and cDNA preparation for gene expression analysis. The qRT-PCR analysis showed that, when $B x S a p B 1$ was silenced, the relative expression levels of the PR genes PtPR- $1 b, P t P R-3$, and PtPR-5 were $0.2218,0.1480$, and 0.3130 , respectively, significantly lower than in $P$. thunbergii inoculated with $G F P$ dsRNA-treated nematodes (Fig. 7). This indicated that BxSapB1 indeed influenced defense responses of $P$. thunbergii.

\section{DISCUSSION}

Many pathogen effectors have been identified by transcriptome sequencing, a rapid and reliable method (Ali et al. 2015a; Bauters et al. 2014; Espada et al. 2016; Haegeman et al. 2013). In the present study, we characterized B. xylophilus transcription during the early stages of infection $(6,12$, and $24 \mathrm{~h}$ after inoculation) to identify candidate effectors. Subsequently, we conducted transient expression of the candidate effectors in the model plant $N$. benthamiana for functional analysis. Functions for many pathogen effectors have been studied using this strategy (Li et al. 2015b; Ma et al. 2015). We successfully identified and characterized an effector named BxSapB1. The transient expression of candidate effectors via viral vectors in $N$. benthamiana proved feasible to identify effectors of B. xylophilus. In this study, pectate lyase, putative endoglucanase, zinc metalloproteinase, and cysteine proteinase were predicted as candidate effectors, which were significantly upregulated during infection, with potential roles in pathogenicity and parasitism (Espada et al. 2016; Qiu et al. 2013). In addition, four of the PWN candidate effectors identified in a previous study (Espada et al. 2016) were also among our 69 candidate effectors. The difference between our list of candidate effectors and the other list might be attributed to the different sampling timepoints in our study.

Recently, new criteria were proposed for the prediction of novel effector genes in B. xylophilus; if a protein has a specific promoter motif (STATAWAARS) and encodes a signal peptide, it is predicted to be an effector. In the promoter motif, positions 5 and 8 are invariably adenine (A) (Espada et al. 2018). We examined the $300 \mathrm{bp}$ upstream of the predicted coding region of $\mathrm{BxSapB} 1$ in order to confirm the presence of the STATAWAARS motif and found that, although BxSapB1 has a promoter motif with a different nucleotide (STATAWAASS instead of STATAWAARS), both positions 5 and 8 are A. It was speculated that the number of candidate effectors (42 genes) used by Espada et al. (2018) was not sufficient to identify all possible promoter motifs of effectors in B. xylophilus. Nevertheless, it was reassuring to see some cross-validation between the two studies.

The results of the present study indicated that novel effector BxSapB1 may be secreted into plants. BxSapB1 contained an $\mathrm{N}$-terminal signal peptide, which is considered to be a characteristic of secreted proteins. Subsequently, the BxSapB1 signal peptide proved to be functional in yeast. Based on BLAST analysis, BxSapB1 showed $100 \%$ identity to BUX. s00139.62, which was a secreted protein identified from the B. xylophilus secretome during $P$. thunbergii infection (Cardoso et al. 2016; Shinya et al. 2013), indicating that BxSapB1 was a secreted protein. BxSapB1 was expressed exclusively in the subventral gland cells, one of the sources of nematode secretory effector proteins (Eves-van den Akker et al. 2016; Toruño et al. 2016).

qRT-PCR analysis showed that the transcription of $B x S a p B 1$ was upregulated in the early parasitic stage of the highly virulent nematode strain AMA3, reaching a maximum level at 12 h. Conversely, it was downregulated in the weakly virulent strain YW4 at the same stage of infection. RNAi assays showed that the appearances of symptoms in $P$. thunbergii were delayed after being infected by BxSapB1-silenced B. xylophilus. These results provided further evidence that $\mathrm{BxSapB} 1$ contributed to the nematode virulence.

Plants launch defenses in the face of attack by pathogens. Among these defense responses is the induction of PR proteins (van Loon et al. 2006). Interestingly, PtPR-1b, PtPR-3, and $P t P R-5$ were downregulated when $P$. thunbergii was infected by BxSapB1-silenced B. xylophilus. This demonstrated that $B x S a p B 1$ is recognized by the plant immune system and might induce $P$. thunbergii defense responses.

Here, BxSapB1 was predicted as a saposin-like protein with a saposin B domain. To the best of our knowledge, this study is the first one to characterize the functions of SAP in B. xylophilus. Previous studies have shown that saposin B could interact with lipid and could promote the degradation of specific sphingolipids (Michalek and Leippe 2015; Yuan et al. 2007). In our study, BxSapB1 triggered cell death independent of NbBAK1 or NbSOBIR1 and it simultaneously contributed to virulence in B. xylophilus. The role of BxSapB1 has some similarity to those of necrosis- and ethylene-inducing-like proteins (NLPs), which are toxin-like virulence factors. NLPs contribute to microbial virulence based upon their ability to permeabilize dicotyledonous plant plasma membranes, thereby causing cytolysis and cell death, which are also independent of BAK1 and SOBIR1 (Ottmann et al. 2009). Moreover, a recent

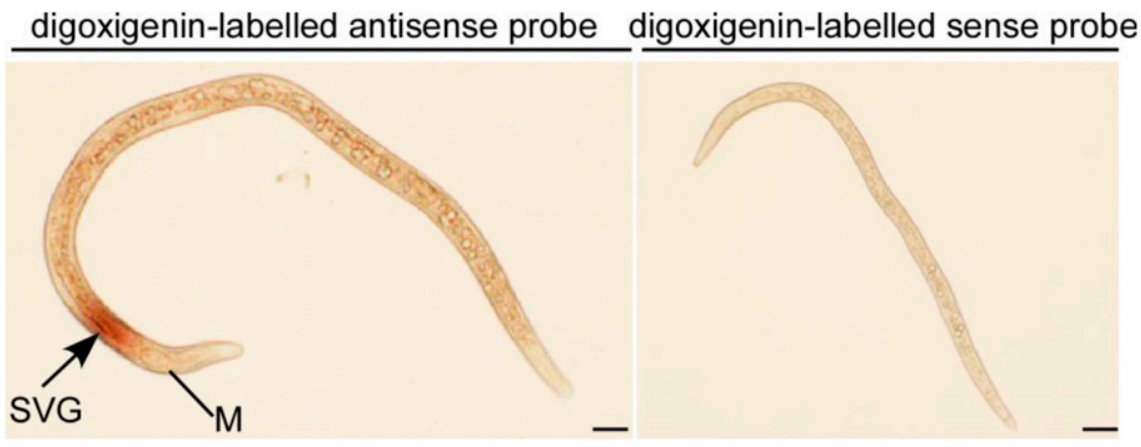

Fig. 4. Localization of $B x \operatorname{SapB} 1 \mathrm{mRNA}$ in subventral gland cells by in-situ hybridization. $\mathrm{M}=$ median bulb, $\mathrm{SVG}=$ subventral glands. Scale bars $=20 \mu \mathrm{m}$. 
study demonstrated that NLPs are recognized by glycosyl inositol phosphorylceramide sphingolipids in plants, which is why NLPs can induce necrosis and facilitate microbial infection of eudicots but not of monocots (Lenarčič et al. 2017). Thus, we speculate that BxSapB1 may also be recognized by specific sphingolipids to trigger cell death in $N$. benthamiana. When B. xylophilus infects $P$. thunbergii, BxSapB1 may interact with specific sphingolipids to facilitate the infection and colonization of B. xylophilus. In addition, it is also possible that BxSapB1 is simply toxic, leading to the cell death in $N$. benthamiana and infection of $B$. xylophilus in $P$. thunbergii.

In this study, BxSapB1 induced cell death in N. benthamiana, which led us to wonder whether it can also trigger cell death in its host, the pinus plants. However, no transient expression system now exists for pines (gymnospermous plants). Moreover, as far as we know, no study has shown whether an effector-induced cell death in $N$. benthamiana could also induce cell death in gymnospermous plants. Attempts to express BxSapB1 in a heterologous system, such as Pichia pastoris, were not successful. Thus, at present, we are unable to determine whether this effector induces cell death in pines.

In summary, we identified a novel effector, BxSapB1 from B. xylophilus, that induced cell death in $N$. benthamiana and contributed to the $B$. xylophilus virulence in pine. Our results shed further light on the mechanisms underlying the interaction between pines and B. xylophilus.

\section{MATERIALS AND METHODS}

\section{Biological material.}

The highly virulent $B$. xylophilus AMA3 strain and the weakly virulent YW4 strain used in this study were respectively from Anhui and Yunnan province, China (Ding et al. 2016). The culture methods of B. xylophilus were similar to the previous report (Qiu et al. 2013). The strains AMA3 and YW4 were transferred to a mycelial mat of Botrytis cinerea growing on PDA plates and were cultured subsequently at $25^{\circ} \mathrm{C}$ for 7 days. Finally, the B. xylophilus were extracted using the Baermann funnel technique.

\section{PWN inoculation and sampling.}

Pinus thunbergii seedlings (3 years old) were obtained from the greenhouse of Nanjing Forestry University and were

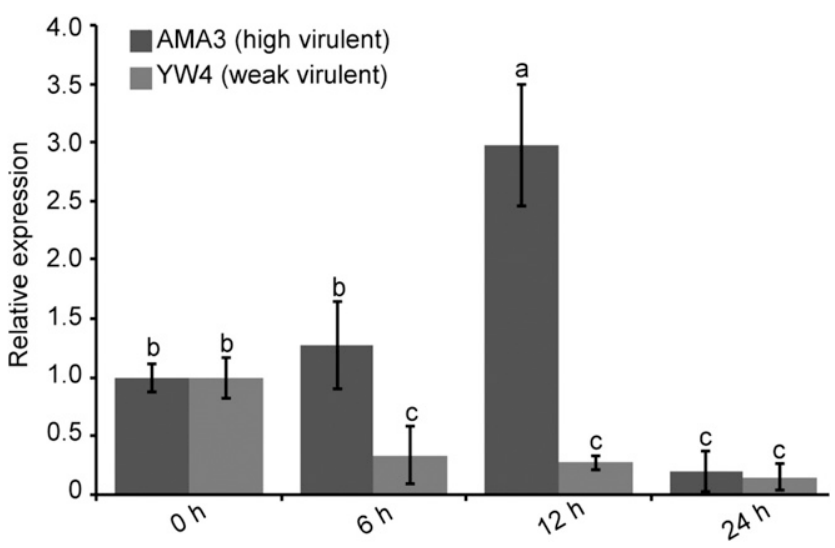

Fig. 5. Different expression patterns of BxSapB1 in highly and weakly virulent strains of Bursaphelenchus xylophilus during the early stages of infection. Data are the means and the error bars represent \pm standard deviation from three biological replicates. Different letters on top of the bars indicate statistically significant differences $(P<0.01, t$ test $)$ as measured by Duncan's multiple range test. cultivated at temperatures ranging from 28 to $32^{\circ} \mathrm{C}$, with a relative humidity from 65 to $75 \%$. A suspension of approximately 10,000 mixed-life-stage nematodes were collected from the PDA as mycophagous control (bx-0 h). In addition, the same number of nematodes (AMA3) were inoculated into a small wound of the pine stems for 6,12 , and $24 \mathrm{~h}$ (bx- $6 \mathrm{~h}, \mathrm{bx}-12$ $\mathrm{h}$, and bx-24 h, respectively). After that, the nematodes were extracted from the whole seedlings for $3 \mathrm{~h}$, using the Baermann funnel technique. After washing three times in double-distilled (dd) $\mathrm{H}_{2} \mathrm{O}$, the nematodes were collected by centrifugation at $3,500 \mathrm{rpm}$ for $3 \mathrm{~min}$ and were then frozen in liquid nitrogen for further RNA isolation. Each treatment had three biological replicates.

\section{RNA isolation, cDNA synthesis, and sequencing.}

Nematode (AMA3) RNA was extracted from bx- 0 h, bx-6 h, bx-12 h, and bx-24 h samples. The RNA extraction was performed using Trizol reagent (Invitrogen), according to the manufacturer's instructions. The RNA degradation and contamination were monitored on $1 \%$ agarose gels. Then the purity, concentration, and integrity of RNA were separately checked by the NanoPhotometer spectrophotometer (Implen), Qubit RNA assay kit in Qubit 2.0 fluorometer (Life Technologies) and the RNA Nano 6000 assay kit of the Bioanalyzer 2100 system (Agilent Technologies). The RNA integrity number of all the samples must be above 7. Subsequently, cDNA library preparations were sequenced on an Illumina HiSeq platform and 150-bp paired-end reads were generated. RNA-Seq data in this study is available through the National Center for Biotechnology Information under accession number PRJNA397001.

\section{Differential gene expression analysis.}

HTSeq v0.6.1 was used to count the read numbers mapped to each gene. For estimating gene expression levels, the DESeq was used to standardize the read count of each gene, which was previously proven better than FPKM (fragment per kilobase per million reads) or RPKM (reads per kilobase million) (Dillies et al. 2013).

Differential expression analysis of four treatments was performed, using the DESeq R package (1.18.0). Based on the negative binomial distribution, DESeq provided statistical routines to determine differential expression in digital gene expression data. The resulting $P$ values were adjusted using Benjamini and Hochberg approach. Genes (with an adjusted $P$ value $<0.05$ and $\log _{2}$ (fold change) $>1$ ) were assigned as differentially expressed between three plant-parasitic timepoints and a mycophagous timepoint. Among the DEGs, upregulated genes had a higher expression at least at one plantparasitic timepoint than at the mycophagous stage, and downregulated genes had a lower expression at all the plant-parasitic timepoints than at mycophagous stage.

\section{Candidate effectors analysis.}

Potentially secreted proteins were identified by using the accepted screening criterion (the presence of an N-terminal signal peptide and the absence of a transmembrane domain). The N-terminal signal peptide and the transmembrane domain were predicted by SignalP 3.0 and TMHMM 2.0, respectively (Bendtsen et al. 2004; Cock and Pritchard 2014). All candidate effectors proceeded to a BLASTP search against the nonredundant database to predict their functions. A BLASTP search against the secretome of $B$. xylophilus was also carried out (Shinya et al. 2013). Furthermore, based on the annotation of the B. xylophilus genome, the putative protein domain description was constructed (Kikuchi et al. 2011). 


\section{Validation of the expression profiles} of the candidate effectors.

The expression levels of 11 DEGs (seven candidate effectors and four downregulated genes) were validated by qRT-PCR, using SYBR green master mix (Vazyme) according to the manufacturer's instructions. The Actin gene of B. xylophilus (GenBank number EU100952) was used as reference for all reactions and the primer information was listed in Supplementary Table S6. Relative expression levels were determined by ABI Prism 7500 software (Applied Biosystems) and was calculated with the $2^{-\Delta \Delta \mathrm{Ct}}$ method (Livak and Schmittgen 2001).

\section{Plasmid constructs.}

The 25 randomly selected candidate effectors with high abundance expression were cloned from the cDNA of B. xylophilus (AMA3), which was synthesized from $50 \mathrm{ng}$ to $5 \mu \mathrm{g}$ of total RNA, using the TransScript II one-step gDNA REMOVAL and cDNA synthesis super mix (TransGen Biotech). The amplified fragments were prepared and ligated into PVX (pGR107), using the appropriate restriction enzymes and Clone Express II One Step cloning kit (Vazyme), respectively. Individual colonies from each construct were tested by PCR for insertions and the selected clones were verified by sequencing.

\section{A. tumefaciens infiltration assays.}

The constructs were inserted into A. tumefaciens GV3101 by electroporation. The transformed bacterial cells were grown on Luria Bertani agar plates with kanamycin and rifampicin. In the agroinfiltration assays, recombinant $A$. tumefaciens strains were grown at $30^{\circ} \mathrm{C}$, in a shaking incubator, at a rotation rate of $200 \mathrm{rpm}$ for 12 to $24 \mathrm{~h}$. Then bacterial cells were collected by centrifugation and, subsequently, were resuspended in washing buffer $(10 \mathrm{mM} \mathrm{MgCl} 2,10 \mathrm{mM}$ morpholineethane sulfonic acid, and $100 \mu \mathrm{M}$ acetosyringone, $\mathrm{pH}$ 5.6). The resuspended $A$. tumefaciens cells were diluted and were mixed with P19 silencing suppressor at a 2:1 ratio to $\mathrm{OD}_{600}=0.4$ for each construct. The infiltration assay was performed three times and, in each assay, three different plants with three inoculated leaves were used.

\section{Yeast signal sequence trap system.}

DNA fragments coding for the signal peptides of BxSapB1 was amplified with the primers and was then introduced into pSUC2, using EcoRI and XhoI restriction sites to create in-frame

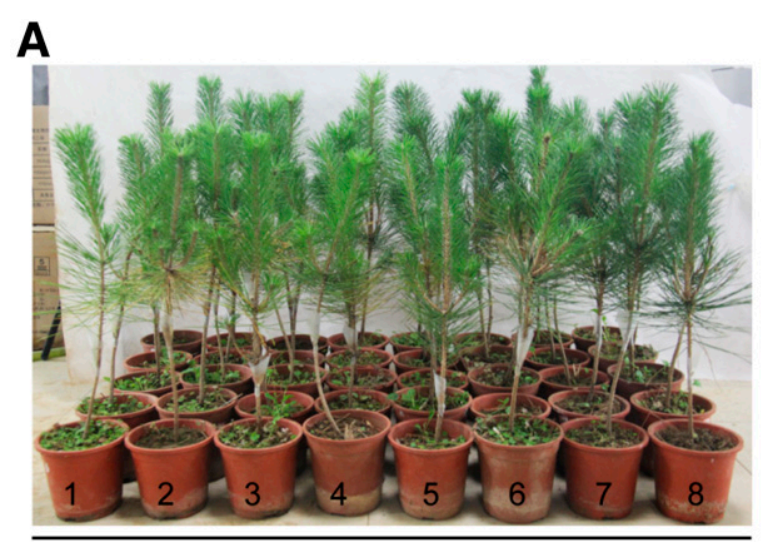

$10 \mathrm{~d}$

B

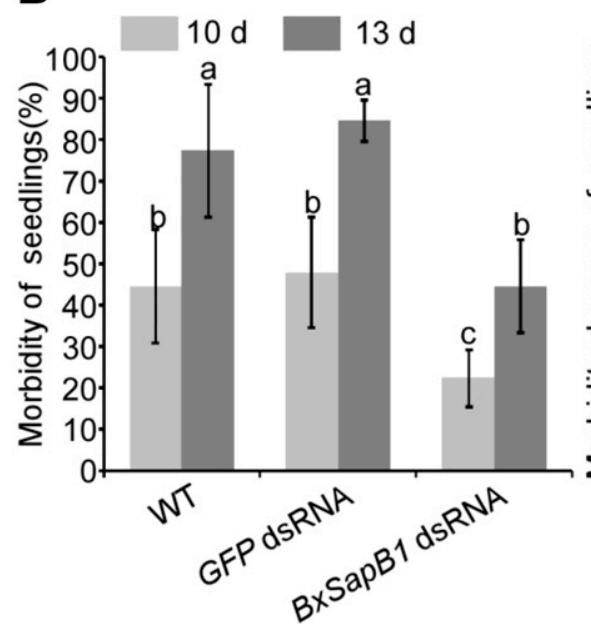

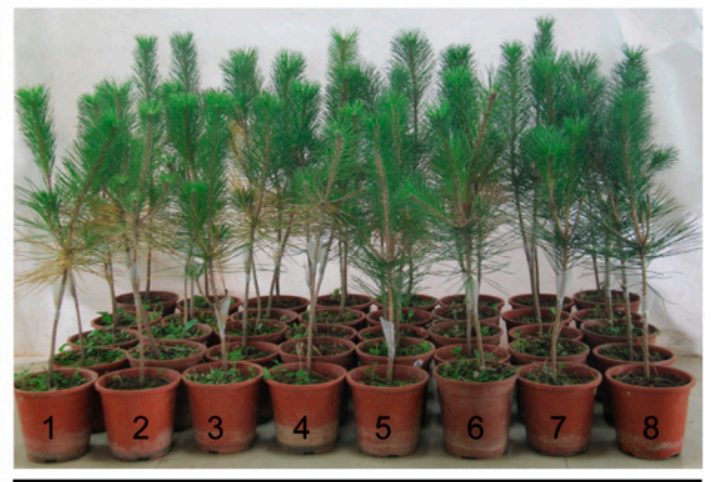

$13 d$

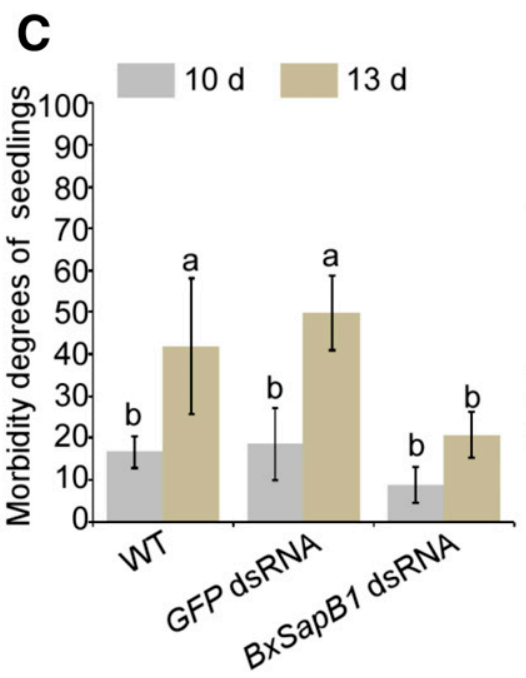

D

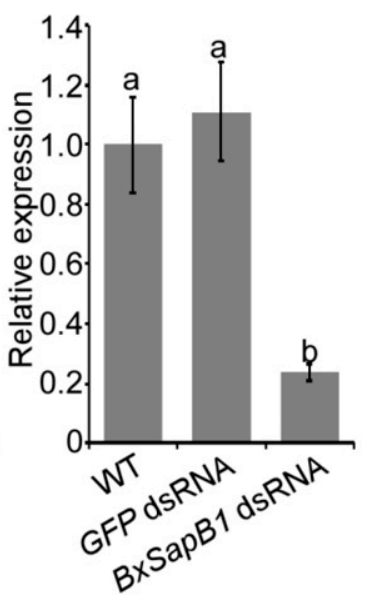

Fig. 6. BxSapB1 contributes to virulence of Bursaphelenchus xylophilus. A, Representative photographs of the inoculation assay. The infection assay was repeated three times and a total of 32 individual Pinus thunbergii seedlings for each treatment were used. Numbers on the pots indicate the following: 1 and 2 , the seedlings inoculated with wild type (WT) nematodes; 3 and 4, the seedlings inoculated with GFP double-stranded RNA (dsRNA)-treated nematodes; 5 and 6, the seedlings inoculated with BxSapB1 dsRNA-treated nematodes; and 7 and 8, the seedlings inoculated only with non-dsRNA solution. B, The morbidity of $P$. thunbergii seedlings under three different treatments. C, The morbidity degrees of $P$. thunbergii seedlings under three different treatments. D, Silencing efficiency after treatment with BxSapB1 dsRNA solution in B. xylophilus. Data are the means and the error bars represent \pm standard deviation from three independent experiments. Different letters on top of the bars indicate statistically significant differences $(P<0.01, t$ test $)$ as measured by Duncan's multiple range test. 
fusions to the invertase. The invertase negative yeast strain YTK12 was transformed with $20 \mathrm{ng}$ of each one of the pSUC2derived plasmids individually, using the lithium acetate method (Gietz et al. 1995). After that, the yeast was plated on CMD-W (minus Trp) plates and YPRAA plates containing raffinose and lacking glucose in turn. In addition, invertase enzymatic activity was detected by reduction of the dye TTC to insoluble red-colored triphenylformazan. These processes were performed as previously described (Oh et al. 2009).

\section{Electrolyte leakage assay.}

The ion leakage from the leaf discs of $N$. benthamiana was measured as described previously (Yu et al. 2012b). Five leaf discs (diameter $9 \mathrm{~mm}$ ) were chosen for each sample and were then suspended in $5 \mathrm{ml}$ of distilled water for $3 \mathrm{~h}$ at room temperature. The conductivity of the bathing solution was measured with a conductivity meter (S470 Seven Excellence; Mettler Toledo) to obtain 'value A'. Afterward, the leaf discs were then returned and were boiled in 10-ml centrifuge tubes for $30 \mathrm{~min}$. When the solution was cooled down to room temperature, the conductivity was measured again to obtain 'value B'. Ion leakage was evaluated by the formula (value A/value B) $\times 100 \%$. The experiment was performed three times.

\section{The silencing of $N b B A K 1$ and $N b S O B I R 1$ in $N$. benthamiana.}

pTRV1, pTRV2:BAK1, pTRV2:SOBIR1, pTRV2:GFP, and pTRV2:PDS plasmid constructs were transformed into A. tumefaciens GV3101. The methods for collecting and resuspending the cultured Agrobacterium cells were the same as above and resuspended $A$. tumefaciens cells were diluted to $\mathrm{OD}_{600}=1.0$. Then, Agrobacterium strains harboring pTRV2: $B A K 1$, pTRV2:SOBIR1, pTRV2:GFP, and pTRV2:PDS vector were first mixed with the strain harboring pTRV1 vector, with a $1: 1$ ratio and the cocultures were then infiltrated into all leaves of a plant at the four-leaf stage. After three to four weeks, the $N$. benthamiana seedlings were infiltrated with PVX::BxSapB1, PVX::INF1, and PVX::NPP1. The phenotypes of $N$. benthamiana were scored at 7 days postinfiltration. The infiltration experiment was performed three times and, in each assay, three different plants with three inoculated leaves were used.

The effectiveness of the VIGS assay was assessed according to the phenotype of $P D S$, as described previously (Liu et al. 2002). The silencing efficiency of $N b B A K 1$ and NbSOBIRI were validated by qRT-PCR. The $N b E F 1 \alpha$ was used as an endogenous control.

\section{Western blot.}

Total protein extraction and immunoblot were performed according to a previous report (Yin et al. 2013). The protein expression in $N$. benthamiana was detected by antihemagglutinin tag primary monoclonal antibody (SigmaAldrich).

\section{In-situ hybridization.}

For in-situ hybridization, approximately 5,000 nematodes of fresh B. xylophilus strain AMA3 were collected. DIG-labeled probes used for in-situ hybridization were prepared according to the protocol as described by de Boer et al. (1998). The DIGlabeled DNA probes were synthesized from the plasmid containing $B x S a p B 1$ by using primers. Hybridization was conducted with the DIG-High Prime DNA labeling and detection starter kit I (Roche Diagnostics), and then, photographs were taken with a Zeiss Axio Image M2 microscope (Zeiss MicroImaging $\mathrm{GmbH}$ ).

\section{The expression patterns of $B x S a p B 1$ at the early stages of infection by $B$. xylophilus strains with different levels of virulence.}

The full-length coding sequence of BxSapB1 was amplified from the cDNA of strains AMA3 and YW4. The amplified fragments were ligated into pMD19-T. The individual colonies from each construct were tested by PCR for insertions and the selected colonies were verified by sequencing. In addition, 10,000 AMA3 and YW4 were inoculated to 3-year-old $P$. thunbergii seedlings and, then, the nematodes were collected at 6,12 , and $24 \mathrm{~h}$ after inoculation, using the Baermann funnel technique. RNA of the two strains was extracted and reversely transcribed into cDNA. Subsequently, the relative expression of $B x S a p B 1$ was detected by qRT-PCR.
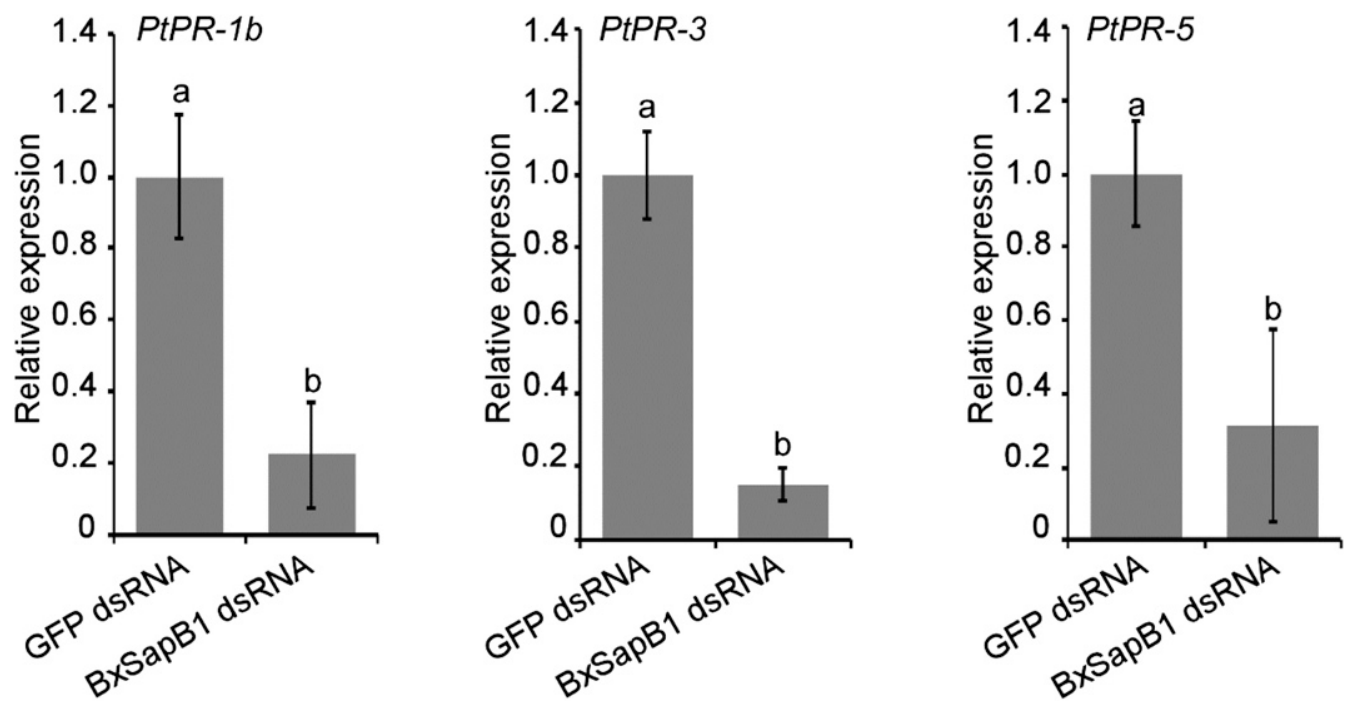

Fig. 7. Relative transcript levels of pathogenesis-related genes in Pinus thunbergii infected with BxSapB1 double-stranded RNA (dsRNA)-treated nematodes. Stems approximately $2 \mathrm{~cm}$ in length were used for RNA extraction at $12 \mathrm{~h}$ postinoculation. This inoculation assay was performed three times and in each assay three different seedlings for each treatment were used. Data are the means and the error bars represent \pm standard deviation from three independent experiments. Different letters on top of the bars indicate statistically significant differences $(P<0.01, t$ test $)$. 
In vitro RNAi of the BxSapB1 gene and inoculation assay.

The dsRNAs corresponding to $B x \operatorname{SapBl}$ and the negative control GFP were synthesized, using the MEGscript RNAi kit (Ambion Inc.), according to the manufacturer's instructions. Afterward, the nematodes (a mixture of juveniles and adults) were soaked in BxSapB1 dsRNA, GFP dsRNA, and nondsRNA solutions and, then, were incubated at $20^{\circ} \mathrm{C}$ in a shaking incubator with a rotation rate of $180 \mathrm{rpm}$ for $48 \mathrm{~h}$. The nematodes from each treatment were thoroughly washed with $\mathrm{ddH}_{2} \mathrm{O}$ three times, after soaking. Subsequently, approximately 2,000 nematodes from three different treatments were collected to evaluate the silencing efficiency of $B x S a p B 1$, by qRT-PCR.

In the infection assay, each 3 -year-old $P$. thunbergii seedling was inoculated with 2,000 nematodes previously soaked in BxSapBl dsRNA, GFP dsRNA, or non-dsRNA solution. The seedlings inoculated only with non-dsRNA solution were regarded as a blank control. Based on the color of the needles, the morbidity degree of the $P$. thunbergii seedlings was classified into five different grades: 0, all needles are green; I, a few needles have turned yellow; II, approximately half of the needles have turned yellow or brown; III, most of the needles have turned brown; and IV, the entire seedling has withered. The morbidity of seedlings was calculated using the formula $A / C$, and the degree of morbidity was calculated using the formula $\Sigma(A \times B) /(C \times D) \times 100$, where $A$ is the number of sick seedlings per grade, $B$ is the corresponding grade of the sick seedlings, $C$ is the number of seedlings inoculated in each treatment, and $D$ is the most serious grade. The morbidity and morbidity degrees of $P$. thunbergii seedlings were calculated. The infection assay was performed three times and a total of 32 individual $P$. thunbergii seedlings for each treatment were used.

The method of collecting adult virgin female nematodes was described previously (Wang et al. 2005). In brief, 10 pairs of virgin female and male $B$. xylophilus were picked out from BxSapB1 dsRNA, GFP dsRNA, or non-dsRNA solutions to each PDA plate with Botrytis cinerea and were cultured at $25^{\circ} \mathrm{C}$ for 9 days, respectively. The experiment was performed three times and in each assay three different PDA plates for each treatment were used.

The total RNA of $P$. thunbergii was extracted from each segment of stems. The expression levels of three PR genes (PtPR-1b, PtPR-3, and PtPR-5) of P. thunbergii were detected using qRT-PCR. The Elongation factor-1 alpha was used as an endogenous control (Hirao et al. 2012). This inoculation assay was performed three times and in each assay three different seedlings for each treatment were used.

\section{ACKNOWLEDGMENTS}

We are grateful to D.-W. Li (Connecticut Agricultural Experiment Station, Windsor, CT, U.S.A.) and D. Krapf (Khonkaenwittayayon School, Khon Kaen, Thailand) for editing this work.

\section{LITERATURE CITED}

Akiba, M., Ishihara, M., Sahashi, N., Nakamura, K., Ohira, M., and Toda, T. 2012. Virulence of Bursaphelenchus xylophilus isolated from naturally infested pine forests to five resistant families of Pinus thunbergii. Plant Dis. 96:249-252.

Ali, S., and Bakkeren, G. 2011. Fungal and oomycete effectors-strategies to subdue a host. Can. J. Plant Pathol. 33:425-446.

Ali, S., Magne, M., Chen, S., Côté, O., Stare, B. G., Obradovic, N., Jamshaid, L., Wang, X., Bélair, G., and Moffett, P. 2015a. Analysis of putative apoplastic effectors from the nematode, Globodera rostochiensis, and identification of an expansin-like protein that can induce and suppress host defenses. PLoS One 10:e0115042.

Ali, S., Magne, M., Chen, S., Obradovic, N., Jamshaid, L., Wang, X., Bélair, G., and Moffett, P. 2015b. Analysis of Globodera rostochiensis effectors reveals conserved functions of SPRYSEC proteins in suppressing and eliciting plant immune responses. Front. Plant Sci. 6:623.

Bauters, L., Haegeman, A., Kyndt, T., and Gheysen, G. 2014. Analysis of the transcriptome of Hirschmanniella oryzae to explore potential survival strategies and host-nematode interactions. Mol. Plant Pathol. 15:352-363.

Bendtsen, J. D., Nielsen, H., von Heijne, G., and Brunak, S. 2004. Improved prediction of signal peptides: SignalP 3.0. J. Mol. Biol. 340:783-795.

Bi, F. C., Liu, Z., Wu, J. X., Liang, H., Xi, X. L., Fang, C., Sun, T. J., Yin, J., Dai, G. Y., Rong, C., Greenberg, J. T., Su, W. W., and Yao, N. 2014. Loss of ceramide kinase in Arabidopsis impairs defenses and promotes ceramide accumulation and mitochondrial $\mathrm{H}_{2} \mathrm{O}_{2}$ bursts. Plant Cell 26: 3449-3467.

Cardoso, J. M., Anjo, S. I., Fonseca, L., Egas, C., Manadas, B., and Abrantes, I. 2016. Bursaphelenchus xylophilus and B. mucronatus secretomes: A comparative proteomic analysis. Sci. Rep. 6:39007.

Chen, C., Liu, S., Liu, Q., Niu, J., Liu, P., Zhao, J., and Jian, H. 2015. An ANNEXIN-like protein from the cereal cyst nematode Heterodera avenae suppresses plant defense. PLoS One 10:e0122256.

Chen, J., Lin, B., Huang, Q., Hu, L., Zhuo, K., and Liao, J. 2017. A novel Meloidogyne graminicola effector, MgGPP, is secreted into host cells and undergoes glycosylation in concert with proteolysis to suppress plant defenses and promote parasitism. PLoS Pathog. 13:e1006301.

Chisholm, S. T., Coaker, G., Day, B., and Staskawicz, B. J. 2006. Hostmicrobe interactions: Shaping the evolution of the plant immune response. Cell 124:803-814.

Chronis, D., Chen, S., Lu, S., Hewezi, T., Carpenter, S. C., Loria, R., Baum, T. J., and Wang, X. 2013. A ubiquitin carboxyl extension protein secreted from a plant-parasitic nematode Globodera rostochiensis is cleaved in planta to promote plant parasitism. Plant J. 74:185-196.

Cock, P. J. A., and Pritchard, L. 2014. Galaxy as a platform for identifying candidate pathogen effectors. Pages 3-15 in: Plant-Pathogen Interactions: Methods and Protocols, Vol. 1127, 2nd ed. P. Birch, J. Jones, and J. Bos, eds. Humana Press, Totowa, NJ, U.S.A.

de Boer, J. M., Yan, Y., Smant, G., Davis, E. L., and Baum, T. J. 1998. Insitu hybridization to messenger RNA in Heterodera glycines. J. Nematol. 30:309-312.

Dillies, M. A., Rau, A., Aubert, J., Hennequet-Antier, C., Jeanmougin, M., Servant, N., Keime, C., Marot, G., Castel, D., Estelle, J., Guernec, G., Jagla, B., Jouneau, L., Laloë, D., Le Gall, C., Schaëffer, B., Le Crom, S., Guedj, M., and Jaffrézic, F. 2013. A comprehensive evaluation of normalization methods for Illumina high-throughput RNA sequencing data analysis. Brief. Bioinform. 14:671-683.

Ding, X., Ye, J., Lin, S., Wu, X., Li, D., and Nian, B. 2016. Deciphering the molecular variations of pine wood nematode Bursaphelenchus xylophilus with different virulence. PLoS One 11:e0156040.

Espada, M., Eves-van den Akker, S., Maier, T., Vijayapalani, P., Baum, T., Mota, M., and Jones, J. T. 2018. STATAWAARS: A promoter motif associated with spatial expression in the major effector-producing tissues of the plant-parasitic nematode Bursaphelenchus xylophilus. BMC Genomics 19:553.

Espada, M., Silva, A. C., Eves van den Akker, S., Cock, P. J., Mota, M., and Jones, J. T. 2016. Identification and characterization of parasitism genes from the pinewood nematode Bursaphelenchus xylophilus reveals a multilayered detoxification strategy. Mol. Plant Pathol. 17:286-295.

Espino, A. M., and Hillyer, G. V. 2003. Molecular cloning of a member of the Fasciola hepatica saposin-like protein family. J. Parasitol. 89: 545-552.

Eves-van den Akker, S., Laetsch, D. R., Thorpe, P., Lilley, C. J., Danchin, E. G., Da Rocha, M., Rancurel, C., Holroyd, N. E., Cotton, J. A., Szitenberg, A., Grenier, E., Montarry, J., Mimee, B., Duceppe, M. O., Boyes, I., Marvin, J. M., Jones, L. M., Yusup, H. B., Lafond-Lapalme, J., Esquibet, M., Sabeh, M., Rott, M., Overmars, H., Finkers-Tomczak, A., Smant, G., Koutsovoulos, G., Blok, V., Mantelin, S., Cock, P. J., Phillips, W., Henrissat, B., Urwin, P. E., Blaxter, M., and Jones, J. T. 2016. The genome of the yellow potato cyst nematode, Globodera rostochiensis, reveals insights into the basis of parasitism and virulence. Genome Biol. $17: 124$.

Eves-van den Akker, S., Lilley, C. J., Jones, J. T., and Urwin, P. E. 2014. Identification and characterisation of a hyper-variable apoplastic effector gene family of the potato cyst nematodes. PLoS Pathog. 10:e1004391.

Franco-Orozco, B., Berepiki, A., Ruiz, O., Gamble, L., Griffe, L. L., Wang, S., Birch, P. R. J., Kanyuka, K., and Avrova, A. 2017. A new proteinaceous pathogen-associated molecular pattern (PAMP) identified in Ascomycete fungi induces cell death in Solanaceae. New Phytol. 214:1657-1672.

Fukuda, K. 1997. Physiological process of the symptom development and resistance mechanism in pine wilt disease. J. For. Res. 2:171-181. 
Gietz, R. D., Schiestl, R. H., Willems, A. R., and Woods, R. A. 1995. Studies on the transformation of intact yeast cells by the LiAc/SSDNA/PEG procedure. Yeast 11:355-360.

Haegeman, A., Bauters, L., Kyndt, T., Rahman, M. M., and Gheysen, G. 2013. Identification of candidate effector genes in the transcriptome of the rice root knot nematode Meloidogyne graminicola. Mol. Plant Pathol. 14:379-390.

Haegeman, A., Mantelin, S., Jones, J. T., and Gheysen, G. 2012. Functional roles of effectors of plant-parasitic nematodes. Gene 492:19-31.

Hancock, J. T., Desikan, R., Clarke, A., Hurst, R. D., and Neill, S. J. 2002. Cell signalling following plant_pathogen interactions involves the generation of reactive oxygen and reactive nitrogen species. Plant Physiol. Biochem. 40:611-617.

Heese, A., Hann, D. R., Gimenez-Ibanez, S., Jones, A. M., He, K., Li, J., Schroeder, J. I., Peck, S. C., and Rathjen, J. P. 2007. The receptor-like kinase SERK3/BAK1 is a central regulator of innate immunity in plants. Proc. Natl. Acad. Sci. U.S.A. 104:12217-12222.

Hirao, T., Fukatsu, E., and Watanabe, A. 2012. Characterization of resistance to pine wood nematode infection in Pinus thunbergii using suppression subtractive hybridization. BMC Plant Biol. 12:13.

Hunt, D. J. 2009. Pine wilt disease: A worldwide threat to forest ecosystems. Nematology 11:315-316.

Hussey, R. S. 1989. Disease-inducing secretions of plant-parasitic nematodes. Annu. Rev. Phytopathol. 27:123-141.

Hussey, R. S., and Mims, C. W. 1990. Ultrastructure of esophageal glands and their secretory granules in the root-knot nematode Meloidogyne incognita. Protoplasma 156:9-18.

Jacobs, K. A., Collins-Racie, L. A., Colbert, M., Duckett, M., Golden-Fleet, M., Kelleher, K., Kriz, R., LaVallie, E. R., Merberg, D., Spaulding, V., Stover, J., Williamson, M. J., and McCoy, J. M. 1997. A genetic selection for isolating cDNAs encoding secreted proteins. Gene 198:289-296.

Jaubert, S., Milac, A. L., Petrescu, A. J., de Almeida-Engler, J., Abad, P., and Rosso, M. N. 2005. In planta secretion of a calreticulin by migratory and sedentary stages of root-knot nematode. Mol. Plant-Microbe Interact 18:1277-1284.

Jones, J. D., and Dangl, J. L. 2006. The plant immune system. Nature 444: 323-329.

Jones, J. T., Haegeman, A., Danchin, E. G., Gaur, H. S., Helder, J., Jones, M. G., Kikuchi, T., Manzanilla-López, R., Palomares-Rius, J. E., Wesemael, W. M., and Perry, R. N. 2013. Top 10 plant-parasitic nematodes in molecular plant pathology. Mol. Plant Pathol. 14:946-961.

Jones, J. T., Moens, M., Mota, M., Li, H., and Kikuchi, T. 2008. Bursaphelenchus xylophilus: Opportunities in comparative genomics and molecular host-parasite interactions. Mol. Plant Pathol. 9:357-368.

Kikuchi, T., Cotton, J. A., Dalzell, J. J., Hasegawa, K., Kanzaki, N., McVeigh, P., Takanashi, T., Tsai, I. J., Assefa, S. A., Cock, P. J., Otto, T. D., Hunt, M., Reid, A. J., Sanchez-Flores, A., Tsuchihara, K., Yokoi, T., Larsson, M. C., Miwa, J., Maule, A. G., Sahashi, N., Jones, J. T., and Berriman, M. 2011. Genomic insights into the origin of parasitism in the emerging plant pathogen Bursaphelenchus xylophilus. PLoS Pathog. 7: e1002219.

Kikuchi, T., Jones, J. T., Aikawa, T., Kosaka, H., and Ogura, N. 2004. A family of glycosyl hydrolase family 45 cellulases from the pine wood nematode Bursaphelenchus xylophilus. FEBS Lett. 572:201-205.

Kikuchi, T., Shibuya, H., Aikawa, T., and Jones, J. T. 2006. Cloning and characterization of pectate lyases expressed in the esophageal gland of the pine wood nematode Bursaphelenchus xylophilus. Mol. PlantMicrobe Interact 19:280-287.

Kikuchi, T., Shibuya, H., and Jones, J. T. 2005. Molecular and biochemical characterization of an endo- $\beta-1,3$-glucanase from the pinewood nematode Bursaphelenchus xylophilus acquired by horizontal gene transfer from bacteria. Biochem. J. 389:117-125.

Lebeda, A., Sedlářová, M., Petř̌ivalský, M., and Prokopová, J. 2008. Diversity of defence mechanisms in plant-oomycete interactions: A case study of Lactuca spp. and Bremia lactucae. Eur. J. Plant Pathol. 122: 71-89.

Lee, J. Y., Cho, P. Y., Kim, T. Y., Kang, S. Y., Song, K. Y., and Hong, S. J. 2002. Hemolytic activity and developmental expression of pore-forming peptide, clonorin. Biochem. Biophys. Res. Commun. 296:1238-1244.

Lenarčič, T., Albert, I., Böhm, H., Hodnik, V., Pirc, K., Zavec, A. B., Podobnik, M., Pahovnik, D., Žagar, E., Pruitt, R., Greimel, P., YamajiHasegawa, A., Kobayashi, T., Zienkiewicz, A., Gömann, J., Mortimer, J. C., Fang, L., Mamode-Cassim, A., Deleu, M., Lins, L., Oecking, C., Feussner, I., Mongrand, S., Anderluh, G., and Nürnberger, T. 2017. Eudicot plant-specific sphingolipids determine host selectivity of microbial NLP cytolysins. Science 358:1431-1434.

Li, H. M., Kennedy, M. W., Jones, J., Karim, M., Kikuchi, T., and Moens, M. 2009. Identification of putative expansin-like genes from the pine wood nematode, Bursaphelenchus xylophilus, and evolution of the expansin gene family within the Nematoda. Nematology 11:355-364.

Li, J., Yin, J., Rong, C., Li, K. E., Wu, J. X., Huang, L. Q., Zeng, H. Y., Sahu, S. K., and Yao, N. 2016. Orosomucoid proteins interact with the small subunit of serine palmitoyltransferase and contribute to sphingolipid homeostasis and stress responses in Arabidopsis. Plant Cell 28 3038-3051.

Li, S. C., Kihara, H., Serizawa, S., Li, Y. T., Fluharty, A. L., Mayes, J. S., and Shapiro, L. J. 1985. Activator protein required for the enzymatic hydrolysis of cerebroside sulfate. Deficiency in urine of patients affected with cerebroside sulfatase activator deficiency and identity with activators for the enzymatic hydrolysis of GM1 ganglioside and globotriaosylceramide. J. Biol. Chem. 260:1867-1871.

Li, Y., Wang, K., Xie, H., Wang, Y. T., Wang, D. W., Xu, C. L., Huang, X., and Wang, D. S. 2015a. A nematode calreticulin, Rs-CRT, is a key effector in reproduction and pathogenicity of Radopholus similis. PLoS One 10:e0129351.

Li, Y., and Ye, J. R. 2008. Death manner of host parenchymatous cells in infecting early stage of pine wilt disease. Sci. Silvae Sin. 44:95-98 (in Chinese)

Li, Z., Yin, Z., Fan, Y., Xu, M., Kang, Z., and Huang, L. 2015b. Candidate effector proteins of the necrotrophic apple canker pathogen Valsa mali can suppress BAX-induced PCD. Front. Plant Sci. 6:579.

Liebrand, T. W., van den Burg, H. A., and Joosten, M. H. 2014. Two for all: Receptor-associated kinases SOBIR1 and BAK1. Trends Plant Sci. 19: 123-132.

Liu, Y., Schiff, M., Marathe, R., and Dinesh-Kumar, S. P. 2002. Tobacco Rar1, EDS1 and NPR1/NIM1 like genes are required for N-mediated resistance to tobacco mosaic virus. Plant J. 30:415-429.

Livak, K. J., and Schmittgen, T. D. 2001. Analysis of relative gene expression data using real-time quantitative PCR and the $2^{-\Delta \Delta \mathrm{Ct}}$ method. Methods 25:402-408

Lozano-Torres, J. L., Wilbers, R. H. P., Warmerdam, S., Finkers-Tomczak, A., Diaz-Granados, A., van Schaik, C. C., Helder, J., Bakker, J., Goverse, A., Schots, A., and Smant, G. 2014. Apoplastic venom allergen-like proteins of cyst nematodes modulate the activation of basal plant innate immunity by cell surface receptors. PLoS Pathog. 10:e1004569.

Ma, Z., Song, T., Zhu, L., Ye, W., Wang, Y., Shao, Y., Dong, S., Zhang, Z., Dou, D., Zheng, X., Tyler, B. M., and Wang, Y. 2015. A Phytophthora sojae glycoside hydrolase 12 protein is a major virulence factor during soybean infection and is recognized as a PAMP. Plant Cell 27: 2057-2072

Mamiya, Y. 2012. Scanning electron microscopy of Pine seedling wood tissue sections inoculated with the Pinewood nematode Bursaphelenchus xylophilus previously prepared for light microscopy. J. Nematol. 44: 255-259.

Michalek, M., and Leippe, M. 2015. Mechanistic insights into the lipid interaction of an ancient saposin-like protein. Biochemistry 54 1778-1786.

Mitchum, M. G., Hussey, R. S., Baum, T. J., Wang, X., Elling, A. A., Wubben, M., and Davis, E. L. 2013. Nematode effector proteins: An emerging paradigm of parasitism. New Phytol. 199:879-894.

Oh, S. K., Young, C., Lee, M., Oliva, R., Bozkurt, T. O., Cano, L. M., Win, J., Bos, J. I., Liu, H. Y., van Damme, M., Morgan, W., Choi, D., Van der Vossen, E. A., Vleeshouwers, V. G., and Kamoun, S. 2009. In planta expression screens of Phytophthora infestans RXLR effectors reveal diverse phenotypes, including activation of the Solanum bulbocastanum disease resistance protein Rpi-blb2. Plant Cell 21:2928-2947.

Ottmann, C., Luberacki, B., Küfner, I., Koch, W., Brunner, F., Weyand, M., Mattinen, L., Pirhonen, M., Anderluh, G., Seitz, H. U., Nürnberger, T., and Oecking, C. 2009. A common toxin fold mediates microbial attack and plant defense. Proc. Natl. Acad. Sci. U.S.A. 106:10359-10364.

Patel, N., Hamamouch, N., Li, C., Hewezi, T., Hussey, R. S., Baum, T. J., Mitchum, M. G., and Davis, E. L. 2010. A nematode effector protein similar to annexins in host plants. J. Exp. Bot. 61:235-248.

Peng, H., Gao, B. L., Kong, L. A., Yu, Q., Huang, W. K., He, X. F., Long, H. B., and Peng, D. L. 2013. Exploring the host parasitism of the migratory plant-parasitic nematode Ditylenchus destuctor by expressed sequence tags analysis. PLoS One 8:e69579.

Qiu, X., Wu, X., Huang, L., Tian, M., and Ye, J. 2013. Specifically expressed genes of the nematode Bursaphelenchus xylophilus involved with early interactions with pine trees. PLoS One 8:e78063.

Shinya, R., Morisaka, H., Kikuchi, T., Takeuchi, Y., Ueda, M., and Futai, K. 2013. Secretome analysis of the pine wood nematode Bursaphelenchus xylophilus reveals the tangled roots of parasitism and its potential for molecular mimicry. PLoS One 8:e67377.

Smant, G., Stokkermans, J. P., Yan, Y., de Boer, J. M., Baum, T. J., Wang, X., Hussey, R. S., Gommers, F. J., Henrissat, B., Davis, E. L., Helder, J., 
Schots, A., and Bakker, J. 1998. Endogenous cellulases in animals: Isolation of $\beta$-1, 4-endoglucanase genes from two species of plantparasitic cyst nematodes. Proc. Natl. Acad. Sci. U.S.A. 95:4906-4911.

Toruño, T. Y., Stergiopoulos, I., and Coaker, G. 2016. Plant-pathogen effectors: Cellular probes interfering with plant defenses in spatial and temporal manners. Annu. Rev. Phytopathol. 54:419-441.

van Loon, L. C. 1985. Pathogenesis-related proteins. Plant Mol. Biol. 4: 111-116.

van Loon, L. C., Rep, M., and Pieterse, C. M. J. 2006. Significance of inducible defense-related proteins in infected plants. Annu. Rev. Phytopathol. 44:135-162.

Vicente, C., Espada, M., Vieira, P., and Mota, M. 2011. Pine wilt disease: A threat to European forestry. Eur. J. Plant Pathol. 133:89-99.

Vieira, P., Danchin, E. G., Neveu, C., Crozat, C., Jaubert, S., Hussey, R. S., Engler, G., Abad, P., de Almeida-Engler, J., Castagnone-Sereno, P., and Rosso, M. N. 2011. The plant apoplasm is an important recipient compartment for nematode secreted proteins. J. Exp. Bot. 62:1241-1253.

Wang, Y., Xu, Y., Sun, Y., Wang, H., Qi, J., Wan, B., Ye, W., Lin, Y., Shao, Y., Dong, S., Tyler, B. M., and Wang, Y. 2018. Leucine-rich repeat receptor-like gene screen reveals that Nicotiana RXEG1 regulates glycoside hydrolase 12 MAMP detection. Nat. Commun. 9:594.

Wang, Y., Suzuki, K., Sakaue, D., and Yamada, T. 2005. Variations in life history parameters and their influence on rate of population increase of different pathogenic isolates of the pine wood nematode, Bursaphelenchus xylophilus. Nematology 7:459-467.

Xiong, J., Lu, H., Lu, K., Duan, Y., An, L., and Zhu, C. 2009. Cadmium decreases crown root number by decreasing endogenous nitric oxide, which is indispensable for crown root primordia initiation in rice seedlings. Planta 230:599-610.

Xu, X. L., Wu, X. Q., Ye, J. R., and Huang, L. 2015. Molecular characterization and functional analysis of three pathogenesis-related cytochrome P450 genes from Bursaphelenchus xylophilus (Tylenchida: Aphelenchoidoidea). Int. J. Mol. Sci. 16:5216-5234.

Yang, B., Wang, Q., Jing, M., Guo, B., Wu, J., Wang, H., Wang, Y., Lin, L., Wang, Y., Ye, W., Dong, S., and Wang, Y. 2017. Distinct regions of the Phytophthora essential effector Avh238 determine its function in cell death activation and plant immunity suppression. New Phytol. 214: 361-375.

Yin, W., Dong, S., Zhai, L., Lin, Y., Zheng, X., and Wang, Y. 2013. The Phytophthora sojae Avr1d gene encodes an RxLR-dEER effector with presence and absence polymorphisms among pathogen strains. Mol. Plant-Microbe Interact 26:958-968.

Yu, L. Z., Wu, X. Q., Ye, J. R., Zhang, S. N., and Wang, C. 2012a. NOSlike-mediated nitric oxide is involved in Pinus thunbergii response to the invasion of Bursaphelenchus xylophilus. Plant Cell Rep. 31:1813-1821.

Yu, X., Tang, J., Wang, Q., Ye, W., Tao, K., Duan, S., Lu, C., Yang, X., Dong, S., Zheng, X., and Wang, Y. 2012b. The RxLR effector Avh241 from Phytophthora sojae requires plasma membrane localization to induce plant cell death. New Phytol. 196:247-260.

Yuan, W., Qi, X., Tsang, P., Kang, S. J., Illarionov, P. A., Besra, G. S., Gumperz, J., and Cresswell, P. 2007. Saposin B is the dominant saposin that facilitates lipid binding to human CD1d molecules. Proc. Natl. Acad. Sci. U.S.A. 104:5551-5556.

Zhang, H., Huang, L., Li, X., Ouyang, Z., Yu, Y., Li, D., and Song, F. 2013. Overexpression of a rice long-chain base kinase gene OsLCBK1 in tobacco improves oxidative stress tolerance. Plant Biotechnol. J. 30:9-16.

Zhang, L., Ni, H., Du, X., Wang, S., Ma, X. W., Nürnberger, T., Guo, H. S. and Hua, C. 2017. The Verticillium-specific protein VdSCP7 localizes to the plant nucleus and modulates immunity to fungal infections. New Phytol. 215:368-381.

Zhang, S., and Xu, J. R. 2014. Effectors and effector delivery in Magnaporthe oryzae. PLoS Pathog. 10:e1003826. 